\title{
Immunoscintigraphy for detecting acute myocardial infarction without electrocardiographic changes
}

\author{
Diwakar Jain, Avijit Lahiri, Edward B Raftery
}

\begin{abstract}
Objective-To establish whether immunoscintigraphy with antibody to myosin may detect acute myocardial infarction without electrocardiographic changes.

Design-Prospective study of patients with suspected acute myocardial infarction or unstable angina with cardiac imaging with "'indium myosin antibody, estimation of cardiac enzyme concentrations, electrocardiography, ${ }^{201}$ thallium imaging, and radionuclide ventriculography.
\end{abstract}

Setting-Coronary care unit in a district general hospital.

Patients - 119 Consecutive patients with suspected acute myocardial infarction or unstable angina. Patients with cardiomyopathy, myocarditis, valvular heart disease, myocardial infarction or cardiac surgery in the previous two weeks or with left bundle branch block and women of childbearing age were excluded.

Results-Of 75 patients with suspected acute myocardial infarction, seven had no diagnostic electrocardiographic changes despite normal conduction patterns. Immunoscintigraphy with myosin antibody disclosed necrosis in all seven patients, which was localised in regions supplied by diseased coronary arteries in all but one. Six patients had abnormal images on ${ }^{201}$ thallium imaging, and all seven had abnormal wall motion at the site of antibody uptake. One patient with minimal left main stem and right coronary artery atheroma had uptake of antibody at two discrete sites.

Conclusions - Immunoscintigraphy with antibody to myosin confirms myocardial infarction in the absence of electrocardiographic changes and discloses the site of infarction.

\section{Introduction}

The diagnosis of acute myocardial infarction is based on typical chest pain, evolving electrocardiographic changes, and increased concentrations of serum cardiac enzymes. Patients commonly present, however, with chest pain and a small increase in cardiac enzyme concentrations but with no electrocardiographic changes of acute myocardial infarction. Several noncardiac conditions may also produce a small increase in cardiac enzyme concentrations, even in the $\mathrm{MB}$ isoenzyme of creatine kinase.' This observation has lent impetus to the development of a new imaging technique that may be used to detect and localise necrotic myocardium.' Experimental studies have shown that antibody against the cardiac contractile protein myosin binds specifically to the myocardial cells if there is irreversible injury to the cell membrane. ${ }^{3}$ When the antibody is labelled with a radioactive isotope a standard gammacamera can be used to localise experimental ${ }^{+}$and human myocardial infarc- tions $^{2}$; this technique has a high sensitivity and specificity.

We describe the use of myosin antibody labelled with indium-111 as a diagnostic tool in patients with suspected acute myocardial infarction without electrocardiographic changes.

\section{Patients and methods}

One hundred and nineteen consecutive patients admitted to the coronary care unit of this hospital with chest pain $<48$ hours duration suspected to be due to acute myocardial infarction or unstable angina had immunoscintigraphy with "'In myosin antibody. Patients with cardiomyopathy, myocarditis, valvular heart disease, myocardial infarction, or cardiac surgery in the preceding two weeks or those in whom the electrocardiogram showed left bundle branch block were excluded, as were women of childbearing age. Twelve lead electrocardiograms were performed at the time of admission, during episodes of chest pain, and daily during the period of hospital stay. Blood samples were collected six to eight hourly for 48-72 hours for estimating total serum creatine kinase concentration and its $M B$ isoenzyme concentration. The Fab fraction of murine monoclonal myosin antibody $(0.5 \mathrm{mg})$ (Myoscint, Centocor, United States) was labelled with 74-83 MBq of "'In and was injected intravenously soon after admission. Planar gammacamera imaging was performed in three standard views (anterior, left anterior oblique, and left lateral) at 24 and 48 hours after the injection of tracer.

The scans were compared with conventional noninvasive radionuclide techniques: scanning with thallium-201 for assessing regional blood flow of the myocardium and ${ }^{99 \mathrm{~m}} \mathrm{Tc}$ blood pool scanning for assessing abnormalities of the left ventricular chamber (abnormal wall motion and ejection fraction). The ${ }^{201} \mathrm{Tl}$ scans were performed during the second (48 hour) imaging with labelled myosin antibody with identical views and $740 \mathrm{MBq}$ of ${ }^{201} \mathrm{Tl}$. Blood pool scans were obtained two to six weeks later with the in vivo labelling method for red cells and $740 \mathrm{MBq}{ }^{99 m} \mathrm{Tc}$. The "gated" images were acquired in the same three views, from which abnormal wall motion was defined and ejection fraction was calculated. Selective coronary arteriography was also performed at two to six weeks.

The diagnosis of acute myocardial infarction was based on the presence of at least two of the three standard criteria: chest pain, increased cardiac enzyme concentration, and evolving electrocardiographic changes. The patients were classified into three diagnostic categories: acute myocardial infarction, unstable angina, and no evidence of acute myocardial infarction or resting ischaemia.

The images obtained with labelled myosin antibody were interpreted independently for evidence of abnormal uptake of tracer and its localisation in the 


\begin{tabular}{|c|c|c|c|c|c|c|c|c|c|}
\hline $\begin{array}{l}\text { Case } \\
\text { No }\end{array}$ & Age & Sex & $\begin{array}{l}\text { Previous } \\
\text { myocardial } \\
\text { infarction }\end{array}$ & Coronary artery affected (\%) & $\begin{array}{l}\text { Peak creatine } \\
\text { kinase } \\
\text { (IU/l) }\end{array}$ & $\begin{array}{l}\text { Location of uptake of "'In labelled } \\
\text { antibody to myosin }\end{array}$ & $\begin{array}{c}\text { s'Tl } \\
\text { perfusion } \\
\text { defect }\end{array}$ & $\begin{array}{c}\text { Wall } \\
\text { motion } \\
\text { abnormality }\end{array}$ & $\begin{array}{l}\text { Left ventricular } \\
\text { ejection } \\
\text { fraction }\end{array}$ \\
\hline 1 & 41 & M & - & Left circumflex $(100)$ & 1205 & Apex & _- & + & 76 \\
\hline 2 & 50 & $\mathrm{M}$ & - & Left main $(<25)$ & 844 & Two discrete sites & + & + & 69 \\
\hline 3 & 48 & $\mathrm{M}$ & - & Left anterior descending (50) & 429 & Anterior wall & + & + & 47 \\
\hline 4 & 62 & $\mathrm{M}$ & - & Left anterior descending (99) & 559 & Apex & + & + & 58 \\
\hline 5 & 65 & $\mathrm{M}$ & - & Left circumflex $(95)$ & 382 & Apex, lateral wall & + & + & 57 \\
\hline 6 & 46 & $\mathrm{M}$ & Inferior wall & Left circumflex (100) & 945 & Lateral wall & + & + & 52 \\
\hline \multirow[t]{2}{*}{7} & 79 & F & Anterior and & Left anterior descending, right coronary & & & & & \\
\hline & & & inferior wall & artery $(100)$ & 823 & Lateral wall, interventricular septum & + & + & 26 \\
\hline
\end{tabular}

$+=$ Present, $-=$ absent

myocardium. The images obtained with ${ }^{201}$ thallium were interpreted for any evidence of abnormalities of myocardial perfusion. ${ }^{6}$ The blood pool ventriculograms were analysed for abnormalities in wall motion, and the left ventricular ejectionfraction was determined using standard techniques. ${ }^{7}$ All images were interpreted blind by a panel of three expert investigators with standard computer enhanced images.

The study was approved by the hospital ethical committee, and informed consent was obtained from each patient.

\section{Results}

Of the 119 patients who had imaging, 75 had acute myocardial infarction, 17 unstable angina, and 27 no evidence of infarction or resting ischaemia. The images obtained with labelled myosin antibody were of good quality and easy to interpret, and differentiating negative from positive images was not difficult. Seventy four of the 75 patients with acute myocardial infarction had positive images with labelled myosin antibody, seven of whom had typical chest pain and increase in cardiac enzyme concentration but did not have any electrocardiographic evidence of acute myocardial infarction. The table outlines the clinical characteristics and the scintigraphic findings in these patients. Only two out of the seven patients had had a previous myocardial infarction; all but one had significant $(\geqslant 50 \%)$ coronary artery disease on angiography, and localisation of labelled myosin antibody was observed in the myocardial segments supplied by the

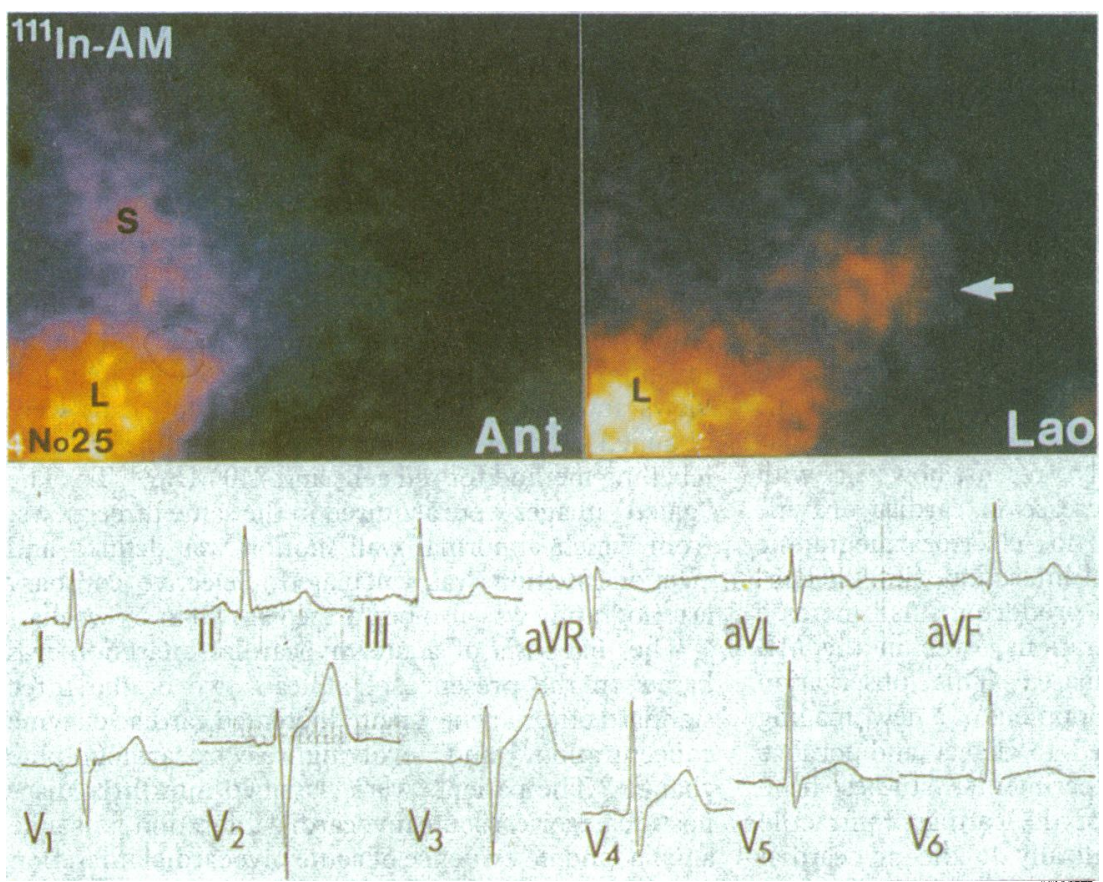

FIG 1-Top: Images with "In labelled antibody to myosin ("'In-AM) in anterior (Ant) and left anterior oblique (Lao) views in patient with acute myocardial infarction without electrocardiographic changes (case 1 in table). Bottom: Electrocardiogram from same patient. $L=$ liver, $S=$ sternum; arrow denotes site of abnormal uptake of antibody in apex diseased coronary arteries (figs 1 and 2). One patient had uptake of the labelled antibody at two discrete sites (fig 2), and the rest all had a single region of uptake involving one or more contiguous walls of the left ventricle. The myocardial infarction in these seven patients was further confirmed by the presence of a localised perfusion abnormality in six and regional wall motion abnormalities in all.

No adverse effects were observed in any patient after administration of labelled myosin antibody, and the blood samples obtained two weeks and six weeks after its injection showed no antibody response.

\section{Discussion}

An appreciable proportion of patients with acute myocardial infarction show no changes on serial electrocardiography. We observed this phenomenon in $9 \%$ of our patients with acute myocardial infarction. Furthermore, it is well known that acute infarction is difficult to diagnose with left bundle branch block, pre-excitation syndromes, and old infarction scars. An alternative method of diagnosing infarction is needed in these patients but in this study we excluded patients with uninterpretable electrocardiograms and concentrated on those with no electrocardiographic changes. The twelve lead electrocardiogram has a low sensitivity for diagnosing small apical, lateral wall, and nontransmural infarctions,${ }^{89}$ but serial estimation of the concentration of enzymes released from the necrotic myocardium into the blood is a more sensitive method of diagnosing acute myocardial infarction. ${ }^{10}$ These estimations are not, however, infallible as cardiac enzyme concentrations may be increased in other conditions. ${ }^{\prime}$ No single cut off point between the normal and abnormal concentrations of creatine kinase and creatine kinase $M B$ can invariably separate infarction from non-infarction. Furthermore, the site of myocardial injury cannot be determined by enzymatic methods.

Direct visualisation of the necrotic myocardium by an imaging technique would plainly be highly valuable. ${ }^{99 \mathrm{~m}}$ Tc-pyrophosphate has been used as a "hot spot" imaging agent for acute myocardial infarction, but the technique is marred by appreciable extracardiac uptake and non-specific uptake by ischaemic (as opposed to necrotic) myocardium. ${ }^{112}$ On the other hand, the specificity of antibodies to myosin for necrotic myocardium has been firmly established in experimenta studies. ${ }^{4}$ In a necroscopic study, when a patient died suddenly after acute myocardial infarction and cardiac rupture after having received "'In labelled antibody 12 hours before death, the sites of uptake of tracer were closely correlated with histologically outlined areas of myocardial necrosis. ${ }^{13}$ Of course, this technique is not specific for acute myocardial infarction alone. Any other condition producing myocardial necrosis (for example, viral myocarditis or transplant rejection) would also result in uptake of the labelled antibody by the heart. ${ }^{14}{ }^{15}$ But the pattern is entirely different in these conditions, producing a picture of generalised uptake quite unlike that observed in acute infarction. 


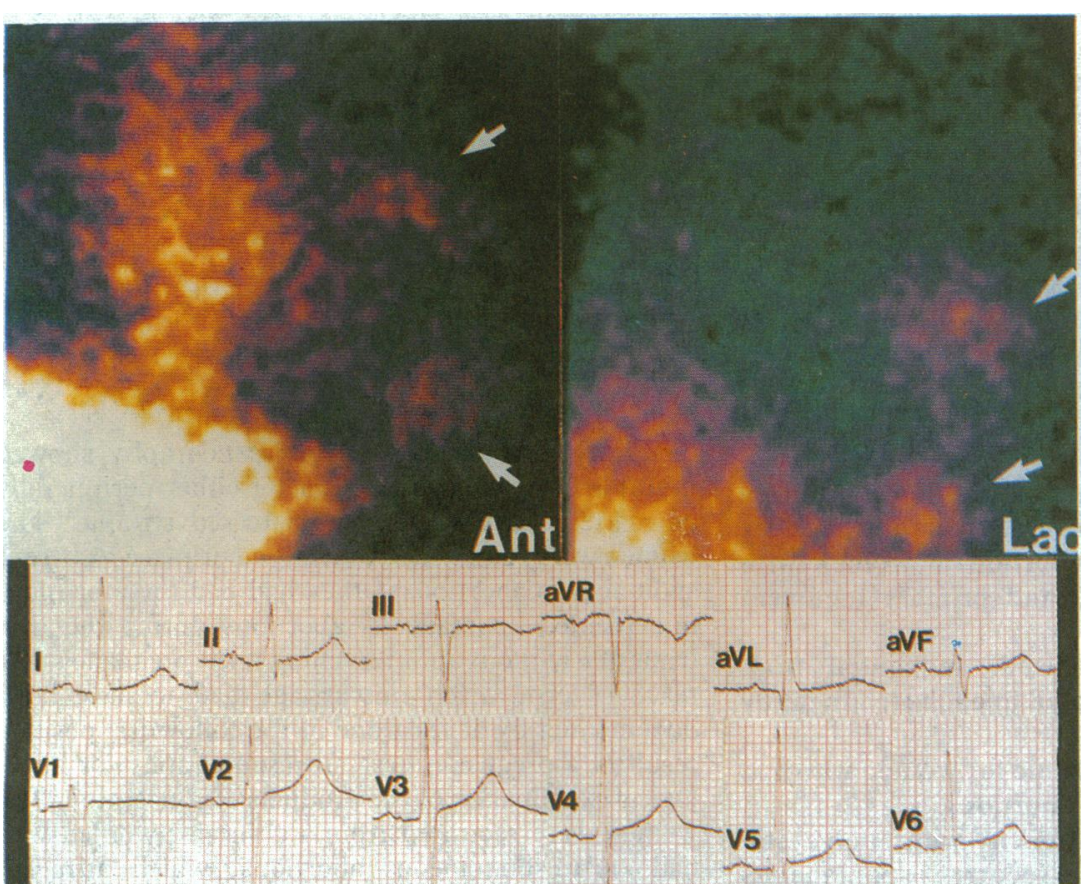

FIG 2-Top: Images with "In labelled antibody to myosin in anterior (Ant) and left anterior oblique (Lao) views in patient with acute myocardial infarction without electrocardiographic changes (case 2 in table), showing discrete uptake of radiotracer at two sites (arrowed). Embolisation from lesion in left main coronary artery may have produced myocardial necrosis at two different sites. Bottom: Electrocardiogram from same patient

Furthermore, there is no evidence that "'In labelled myosin antibody can be taken up by non-necrotic myocardium.

Patients with suspected myocardial infarction but without electrocardiographic or enzymatic evidence of infarction have a similar reported incidence of subsequent cardiac events to those with a positive diagnosis of acute infarction. ${ }^{1617}$ There are several possible explanations for this apparent anomaly; the most likely is that the infarctions were not detected by conventional methods in the group with suspected myocardial infarctions. Imaging with labelled antibody to myosin has also been used for identifying a high risk group after acute myocardial infarction, ${ }^{18}$ and this technique may have wider applications. In our study the site of uptake of the antibody was closely correlated with the abnormalities detected by conventional imaging techniques. The uptake of antibody noted at two discrete sites in a patient with minor plaques in the left main and right coronary arteries (fig l) may have been due to embolic infarction.

Our results indicate that the standard serial 12 lead electrocardiogram may fail to detect acute myocardial infarction in nearly a 10th of patients admitted with typical chest pain and suspected infarction. A definite diagnosis of acute myocardial infarction may be made with imaging "'In antibody to myosin, which seems to be a useful and a safe technique that can be easily carried out in any centre equipped with a gamma- camera. The images are clear and easy to interpret. The technique will, however, need to be refined before it is useful for selecting patients for thrombolytic treatment because a delay of at least 18-24 hours must occur between administering the tracer and cardiac imaging to permit its clearance from the blood. On the other hand, the technique may be useful for objective assessment of myocardial salvage using the wide variety of thrombolytic agents in current use. Experience with this technique so far has been encouraging, and it will be used increasingly in managing patients admitted to coronary care units with suspected acute myocardial infarction.

This study was supported by a grant from Centocor, Malvern, Pennsylvania, United States. We acknowledge the help of Miss Usha Raval and Mr David Hinge in this study.

1 Navin TR, Hager DW. Creatine kinase MB isoenzyme in the evaluation of myocardial infarction. In: Harvey EJ, ed. Current problems in cardiology. Chicago: Year Book Medical Publishers 1979;3:7-32.

2 Khaw BA, Yasuda T, Gold HK, et al. Acute myocardial infarction imagin with indium-111 labelled monoclonal antimyosin Fab. $f$ Nucl Med 1987;28:1671-8.

3 Khaw BA, Scott J, Fallon JT, Cahill SL, Haber E, Homcy C. Myocardial injury: quantitation by cell sorting initiated with antimyosin fluorescent spheres. Science 1982;217:1050-3.

4 Khaw BA, Fallon JT, Beller GA, Haber E. Specificity of the location of myosin specific antibody fragments in experimental myocardial infarction: histologic, histochemical, autoradiographic and scintigraphic studies. histologic, histochemical,
Circulation 1979;60:1527-31.

5 Berger HJ, Lahiri A, Leppo J, et al. Antimyosin imaging in patients with ischaemic chest pain: initial results of phase III multicentre trial [Abstract] f Nucl Med 1988;29:805.

6 O'Hara MJ, Lahiri A, Whittington JR, Crawley JCW, Raftery EB. The detection of high risk coronary artery disease by thallium imaging. Br Heart f 1985;53:616-23.

7 Hains ADB, Al-Khawaja I, Hinge DA, Lahiri A, Raftery EB. Radionuclide left ventricular ejection fraction: a comparison of three methods. $\mathrm{Br}$ Heart $\mathcal{F}$ 1987;57:242-6.

8 Savage RM, Wagner GS, Ideker R, Podosky SA, Hackel DB. Correlation of post mortem anatomic findings with electrocardiographic changes in patients with myocardial infarction: retrospective study of patient

9 Raunio H, Rissanen V, Rompannen T, et al. Changes in QRS complex and ST segment in transmural and subendocardial infarctions. A clinicopathologic segment in transmural and subendocar
study. Am Heart $\mathcal{F}$ 1979;98:176-83.

10 Roberts R, Henry PD, Sobel BE. An improved basis for enzymatic estimation of infarct size. Circulation 1975;52:743-54.

11 Turi ZG, Rutherford JD, Roberts R, et al. Electrocardiographic, enzymatic and scintigraphic criteria of acute myocardial infarction as determined from study of 726 patients (a Milis study). Am $\mathcal{F}$ Cardiol 1985;55:1467-8.

12 Fisher M, Kelemen MH, Collins D, et al. ${ }^{{ }^{{ }_{m}} \mathrm{~T}} \mathrm{~T}$-pyrophosphate scintigraphy in patients with suspected acute myocardial infarction: impact of interobserve variability. Am Heart f 1985; 110:347-52.

13 Jain D, Lahiri A, Crawley JCW, Raftery EB. Post mortem correlation between histopathologic and autoradiographic extent of myocardial necrosis detected by "'In-antimyosin imaging in a patient with acute myocardial infarction. American foumal of Cardiac Imaging 1988;2:158-61.

14 Carrio I, Bena L, Ballester $M$, et al. Indium-111 antimyosin scintigraphy to assess myocardial damage in patients with suspected myocarditis and assess myocardial damage in patients with suspe

15 Hall TS, Baumgartner WA, Borkon AM, et al. Diagnosis of acute cardiac rejection with antimyosin monoclonal antibody, phosphorus nuclear mag rejection with antimyosin monoclonal antibody, phosphorus nuclear mag-
netic resonance imaging, two dimensional echocardiography and endonetic resonance imaging, two dimensional ech
cardial biopsy. F Heant Transplant 1986;5:419-24.

16 Madsen JK, Hansen JF. The prognosis for patients admitted to a coronary care unit due to suspected acute myocardial infarction with and withou confirmed diagnosis. Acta Med Scand 1982;211:453-7.

17 Schroeder JS, Lamb IM, Hu M. Do patients in whom myocardial infarction has been ruled out have a better prognosis after hospitalisation than those surviving infarction? N Engl $\mathcal{A}$ Med 1980;303:1-5.

18 Jain D, Lahiri A, Crawley JCW, Berger H, Raftery EB. Signficance of diffuse uptake of "'In-antimyosin in acute myocardial infarction [Abstract]. Nucl Med Comm 1988;9:163.

(Accepted 17 November 1989

\section{ONE HUNDRED YEARS AGO}

It will be remembered that a law came into force in the State of New York a year ago directing that the death penalty shall in future be inflicted by electricity. A murderer was shortly afterwards found guilty and sentenced to be put to death by this means. He appealed against the sentence on the ground that the law was unconstitutional, the proposed method of execution being cruel and repugnant to public morals. The State Court rejected the appeal, which was then carried to the Supreme Court of the United States. The Supreme Court has decided that the law is constitutional. It is stated that the main opposition has really come from companies holding patents of electrical apparatus of the kind which it is proposed to use in carrying out the capital sentence. Another death from electricity is reported by telegraphic dispatches from New York this week. A horse touched a post which had accidentally become connected with an electric-light wire; the animal was thrown to the ground but not killed, but a man who ran to its assistance, and also touched the post, was instantly struck dead. The coroner's jury, in the case of the shopman who was killed by an electric light wire coming in contact with a showcase which he was helping to carry, has given a verdict throwing the whole responsibility on the electric light company, and the grand jury has indicted the superintendent of lamps to the company for manslaughter. (British Medical Fournal 1890;i:195) 